\title{
Social validation of vocabulary selection: ensuring stakeholder relevance
}

\author{
Juan Bornman ${ }^{1} \&$ Diane Nelson Bryen ${ }^{2}$ \\ ${ }^{1}$ University of Pretoria, Pretoria, South Africa \\ ${ }^{2}$ Temple University, Philadelphia, PA, USA \\ Correspondence: Juan Bornman, Centre for Augmentative and Alternative Communication, University of Pretoria, \\ Pretoria, South Africa. Tel: + 2712420 2001. E-mail: Juan.Bornman@up.ac.za
}

\begin{abstract}
The vocabulary needs of individuals who are unable to spell their messages continue to be of concern in the field of augmentative and alternative communication (AAC). Social validation of vocabulary selection has been suggested as one way to improve the effectiveness and relevance of service delivery in AAC. Despite increased emphasis on stakeholder accountability, social validation is not frequently used in AAC research. This paper describes an investigation of the social validity of a vocabulary set identified in earlier research. Bornman, Bryen, Kershaw, and Ledwaba (2011) used stakeholder focus groups to identify vocabulary that could be used by South African adults who use AAC to disclose their experiences as victims of crime or abuse. (Bryen, Kershaw, and Bornman (2010 used this vocabulary to create communication boards for use by adults with complex communication needs $(\mathrm{CCN}))$. In this current project, 12 South African adults with $\mathrm{CCN}$ who use AAC systems used a five-point Likert scale to score the importance of each of the previously identified 57 vocabulary items. This two-step process of first using stakeholder focus groups to identify vocabulary, and then having literate persons who use AAC provide information on social validity of the vocabulary on behalf their peers who are illiterate, appears to hold promise as a culturally relevant vocabulary selection approach for sensitive topics such as crime and abuse.
\end{abstract}


Keywords: Vocabulary selection; Social validation; Crime and abuse; Developmental delay; Acquired disability; Communication

\section{Introduction}

One of the most welcomed developments in disability research over the past decade has been the acknowledgement that unless people with disabilities, irrespective of their level of receptive or expressive language, are themselves consulted about issues concerning them, there is a serious gap in the research findings (Cambridge \& Forrester-Jones, 2003; Hurst, 2003). In the field of augmentative and alternative communication (AAC), there has been a positive movement towards including adults with complex communication needs $(\mathrm{CCN})$ in all aspects of the research process, and not just as subjects of research (Rackensperger, 2012; Rackensperger, Krezman, McNaughton, Williams, \& D’Silva, 2005; Shane, Blackstone, Vanderheiden, Williams, \& DeRuyter, 2012).

Research informed by people who experience disability is clearly called for when the focus of this research is their experiences as victims of crime and abuse. However, communication problems that are inherent in many disabilities make it difficult for children and adults with disabilities to understand and verbalise episodes of crime or abuse (Knutson \& Sullivan, 1993; Sullivan \& Knutson, 2000). This is particularly difficult when attempting to report these traumatic episodes to the police or when attempting to testify in court (Bryen \& Wickman, 2011). It is therefore important that research methodologies used in studying this sensitive area be effective, bearing in mind that some children and adults with disabilities require 
additional or different forms of support in order to exercise their rights relating to safety and protection. Procedures that will yield accurate evidence of victimization need to be adopted (Sullivan, 2009).

Issues of crime and abuse against persons with disabilities are an international issue (United Nations Enable, 2012), however these challenges may be especially great in multi-lingual countries with high rates of illiteracy such as South Africa. Although there is no single public policy for addressing crime and abuse of individuals with disabilities in South Africa, there have been several significant attempts to address the issues on the rights of children and adults with disabilities who have been victims of crime or abuse (Northway et al., 2004). One of these initiatives is the development and acceptance of non-speech alternatives for communication, better known as AAC.

Despite advances in field of AAC, the vocabulary needs of pre-literate and non-literate children and adults with CCN who are unable to spell their messages continue to be of concern in the AAC community (Beukelman \& Mirenda, 2005). As early as 1981, Carlson noted that, "They [people who use AAC] are unable to create spontaneously their own lexicon and must operate with a vocabulary selected by someone else or preselected, not spontaneously chosen by themselves" (p. 140). Many teams are aware that the vocabulary resource lies at the heart of most AAC systems (Graves, 2000). Unfortunately, one individual or one team rarely has enough knowledge and/or experience to select vocabulary for every specific context, activity, and ethnic or language group (Beukelman \& Mirenda, 2005; Bryen, 2008).

Vocabulary selection is especially critical for the development of age-appropriate and culturally relevant communication boards and speech-generating devices (Bryen, 2008). For 
adults with CCN, vocabulary selection regarding sensitive topics may be even more difficult, as ethnographic approaches such as diary studies or inventories of conversational themes (Graves, 2000) may not be appropriate or feasible. Ideally, adults who use AAC should take a leadership role in identifying this vocabulary; but in reality this is generally not the case. Instead, informants who may or may not know adults who use AAC and their communicative situations are generally the ones to select vocabulary items (Beukelman \& Mirenda, 2005). However, literature has noted that vocabulary selection by communication partners as informants often was inadequate; for example, Shewan and Cameron (1984) suggested that one cannot always rely on using familiar partners as reliable and accurate informants.

In addition to the use of knowledgeable informants, other methods of vocabulary selection have been considered. Some authors have suggested the use of conversational topics to support the communication abilities of adults with, for example, expressive aphasia (Ho, Weiss, Garrett, \& Lloyd, 2005). The aim of these conversational topics is to assist adults with independent initiation of conversation. Use of conversational topics can provide a framework on which conversations can be co-constructed and from which the necessary vocabulary items can be derived (Garrett \& Huth, 2002; Van de Sandt-Koenderman, 2004). Commercially available vocabularies can then provide the necessary vocabulary for adults (Kagan, Winckel, \& Schumway 1996). However, research by Bryen (2008) reported that commercial vocabularies often lack needed vocabularies for dealing with a whole range of adult topics (e.g., college, intimate relations, employment, crime). Furthermore, these commercial vocabularies are not always applicable for the individual circumstances, needs and cultures of people who use AAC in South Africa where there are many indigenous groups and 11 official languages. Studies during the past decade have started to highlight the importance of cultural and social factors and 
how they may influence communication needs (Graves, 2000). However, due to the sensitive nature of some topics, such as abuse or crime victimization, no vocabulary lists for reporting crime or abuse have existed in South Africa until recently.

A recent South African research study that addressed the vocabulary needs of nonspeaking adults who had been victimized and who wanted to disclose their experience, described a method for vocabulary selection (Bornman, Bryen, Kershaw, \& Ledwaba, 2011). Focus groups of speech-language therapists, teachers, parents, and individuals who rely on AAC were used as a means for vocabulary selection. However, Bornman et al. (2011) noted that this method of vocabulary selection should only be seen as the initial step. Subsequent steps should include vocabulary validation by people who are, themselves, users of AAC.

Social validation of vocabulary may be one way to improve the effectiveness and relevance of AAC, and to ensure stakeholder accountability. Using adults who use AAC as key stakeholders to verify vocabulary for illiterate peers, particularly when sensitive topics are at hand, may be an appropriate avenue for social validation.

Social validation is not an entirely new concept. As early as 1978 , Wolf noted its importance and described it as helping to determine the relevance of research questions, the acceptability of treatments, and the importance of research outcomes to society. However, 20 years later, Schlosser (1999) claimed that, in spite of the emphasis on stakeholder accountability, social validation is rarely examined in AAC research. More recently, Sudsawad (2009) again emphasized that social validation is necessary for the effective utilization of disability and rehabilitation research.

The primary aim of this research was to investigate the social validity of the vocabulary identified by Bornman et al (2011) and used on the Communication for All: You can Tell and be 
Heard communication boards (Bryen, Kershaw \& Bornman, 2010), by determining the importance of these vocabulary items to adults who use AAC. The vocabulary on these boards was initially identified by 36 delegates (e.g., teachers, speech-language pathologists, occupational therapists, a psychologist, a counsellor, a criminologist, a criminal lawyer, a disability activist and a young adult who uses AAC) following a workshop on the topic of crime and abuse. The delegates formed four focus groups, and were asked to identify the vocabulary that a person who uses AAC in South Africa would need for disclosing that he/she had been the victim of crime or abuse (Bornman et al., 2011).

Following the identification of the vocabulary, the question remained whether or not the selected vocabulary was considered important to include on a communication board by the primary stakeholders - individuals with $\mathrm{CCN}$ in South Africa. The verification process reported in this article was therefore followed in an attempt to investigate the social validity of this vocabulary..

\section{Method}

In order to address the overall purpose of this study, a descriptive study was used which included the development of survey instrument. Information is provided in this section about the research design, survey, participants, and data analysis.

\section{Research Design}

This study used a non-experimental descriptive survey design (McMillan \& Schumacher, 2010) which allowed the investigators to describe the responses of 12 South African adults who use alphabet-based AAC systems, using a questionnaire based on the vocabulary included in Communication for ALL: You can Tell and be Heard communication board (Bryen et al., 2010). The participants used the questionnaire to provide both demographic information, as well as 
responses on a checklist that was used to assess the social validity of the vocabulary used on the communication boards. The survey design was useful in comparing responses from the present participant group to those of the original research group (Bornman et al., 2011).

\section{Materials}

The questionnaire was comprised of three parts. First, a demographic questionnaire was developed to obtain biographical data from participants. This questionnaire included questions about the following: gender, age, first language, type of disability and whether it was congenital or acquired, the highest level of education, and the type of AAC system used and the length of time that it had been used. It also included a question about whether the checklist was completed independently or with assistance, and finally, a question about whether or not the individual had ever been a victim of crime or abuse.

Second, a checklist was developed based on the vocabulary of the communication boards (Bornman et al., 2011); this checklist formed the main instrument used for data collection. Vocabulary on the checklist consisted of 57 words (shown in Table 1). No words for body parts were included since line drawings of a male and female body were provided on the communication boards, so body parts could be identified by pointing to the line drawing. The checklist contained six columns, with the word in the far left column, followed by a five-point Likert scale which ranged from 1 (not at all important to include), 2 (not important to include), 3 (unsure), 4 (quite important to include), and 5 (very important to include). Items were not randomised but presented alphabetically. The participants were directed to mark one of the five columns to indicate how important each of the vocabulary items would be on a communication board that could be used to disclose their experience a victim of crime or abuse. The third and final component was an open-ended question, asking "Please list any other words that you think 
are important." An alphabetical list enabled study participants to quickly alphabetically scan the list to determine if words that they considered were already on the list.

\section{Participants}

Twelve South African adults with CCN who use AAC participated in this research. Given the low incidence of this disability $-1.3 \%$ of all individuals (Beukelman \& Mirenda, 2005 ) or approximately 650,000 South Africans, the sample size is rather small. Nationwide in South Africa, there is limited or no access to technologies that can augment or provide an alternative to limited speech for persons with disabilities. As such, recruitment of participants was further limited.

Recruitment of participants. The Centre for Augmentative and Alternative Communication at the University of Pretoria in South Africa has an empowerment project aimed at young adults who use AAC. This project, called "Fofa", (the Sesotho word for "to fly" or "to soar" above your difficulties) has been conducted annually since 2005 . It is a week-long project and the participants come from all over South Africa, reflecting the diverse cultural and linguistic profile of the country. Typically, between 8 and 10 participants are annually invited to attend. Selection and participation criteria for attending the Fofa programme are set and most participants attend the one-week project for between one and four years.

Because no other adult group of persons who use alphabet-based AAC exists in South Africa, it was decided to recruit participants for this study from the Fofa group. The recruitment procedure was two-fold. Firstly, an e-mail was sent to Fofa alumni explaining the nature of the project and outlining what was expected of them. A letter requesting their consent was prepared, written in Easy English and analysed as being on a grade 4 reading level, using the FleschKincaid Grade Level computer analysis in Microsoft Word (English U.S.) (McClure, 1987). A 
reminder was emailed two weeks later. From the 9 e-mails sent, three were returned before the specified cut-off date. A second email was sent, announcing an extension of two weeks. One more individual completed and returned the questionnaire. Since one person had passed away shortly after the e-mails had been sent, this initial response rate was 50\%. All participants were assured of confidentiality by notifying them that all identifying information would be removed from the final report. However, given that the participants were all known to the researchers and their identities were apparent from their email addresses, as well as the sensitive nature of some of the questions (e.g., Have you ever been a victim of crime or abuse?), a response rate of only $50 \%$ might have been expected. Three of the 4 checklists that were returned electronically were completed independently. The fourth checklist was completed with the physical assistance from another person as an accommodation for access difficulties.

As a follow-up to recruiting via email and to ensure that alternative formats for responding were provided, Fofa participants were asked if they wanted to participate during the training week when they were on the university campus. Apart from the 4 Fofa alumni who had already returned their questionnaires electronically, all 8 Fofa participants attending the 2011 week provided consent. Of these 8 participants, only two were able to complete the checklist independently. The others needed physical assistance in completing the survey due to access difficulties. The two methods of recruitment, email and face-to-face, resulted in a total of 12 participants. No individual failed to provide consent to participate in the study.

Description of participants. The majority of the participants were male $(n=8)$. The most common medical diagnosis was cerebral palsy $(n=8)$. The remaining 4 had diverse diagnoses: 1 participant sustained a traumatic brain injury more than six years ago and another more than five years ago; 1 participant had a viral brain infection (more than 6 years ago) and another had a 
degenerative muscle condition. One-third of the participants $(n=4)$ indicated that they had been victims of crime or abuse.

The ages of the participants ranged from 19 to 39 , with an average age of 27 years. All participants had some kind of formal education, although the level varied considerably. Five had an educational level of between grades 8 and 11. Two participants had an education level of lower than grade 7 , while 2 had a grade-12 certificate, meaning they had successfully graduated from school. Two obtained educational diplomas after having left school and one had a university degree.

Half of the participants were unemployed, while 4 stated that they were self-employed; 1 participant was volunteering full-time, and 1 was volunteering part-time. Despite being selfemployed, these individuals still relied on disability grants for subsistence. In South Africa, up to $99 \%$ of adults with disabilities are unemployed, poor and unable to live independently (White Paper, 1995).

All participants had English literacy skills, but only 4 used it as a first language, with the rest using it as either a second or a third language. However, all participants used English text-tospeech devices, because commercially available text-to-speech devices are not yet available in most of the indigenous South African languages. Apart from the 4 participants who used English as their first language, 3 used isiZulu, 3 Afrikaans, 1 isiNdebele and 1 Setswana.

The range of AAC devices also varied. Due to the cost of dedicated devices, only 2 individuals used this type of AAC, namely a Pathfinder Plus (www.prentrom.com) and a Lightwriter SL40 (http//:www.toby- churchill.com). The latter was used without speech output (own preference) because the user's first language was not English. This participant also made use of a laptop with E-triloquist (http//:www.etriloquist.com/), formerly known as "SpeakEasy", 
(E-triloquist). The rest of the participants used non-dedicated devices (10 laptops and one iPod Touch). Proloquo2Go software (http//:www.assistiveware.com/) was loaded on the iPod Touch and was used by the only ambulatory user of AAC in the group whose fine motor skills were good. The 8 individuals who did not need mobile devices and who used laptops, mostly used The Grid software (www sensorysoftware.com/thegrid2 html), with two using E-Triloquist on the laptop. Despite the fact that all 12 participants had access to low tech alphabet boards and used them to varying degrees, only 2 participants listed alphabet-based communication boards as part of their AAC system.

\section{Data Analysis}

In keeping with the selected research design, descriptive statistics formed the basis for the data analysis procedure (McMillan \& Schumacher, 2010). Responses from the demographic questionnaire and vocabulary checklist were entered on a Microsoft Excel spreadsheet.

Frequencies, percentages, means, and ranges were subsequently calculated for purposes of analysis.

\section{Results}

The 12 participants used a 5-point Likert-scale to indicate the importance of each of the 57 vocabulary items (Bornman et al., 2011; Bryen et al., 2010) that could be used to disclose their experience as a victim of crime or abuse. Overall, the results demonstrated that, across all participants and all words, $80 \%$ of the words were considered either very important to include or quite important to include in a communication aid designed to enable a person with $\mathrm{CCN}$ to tell that they have been a victim of crime or abuse. 
Table 1 : Frequency of Likert Scale Ratings for Each Word

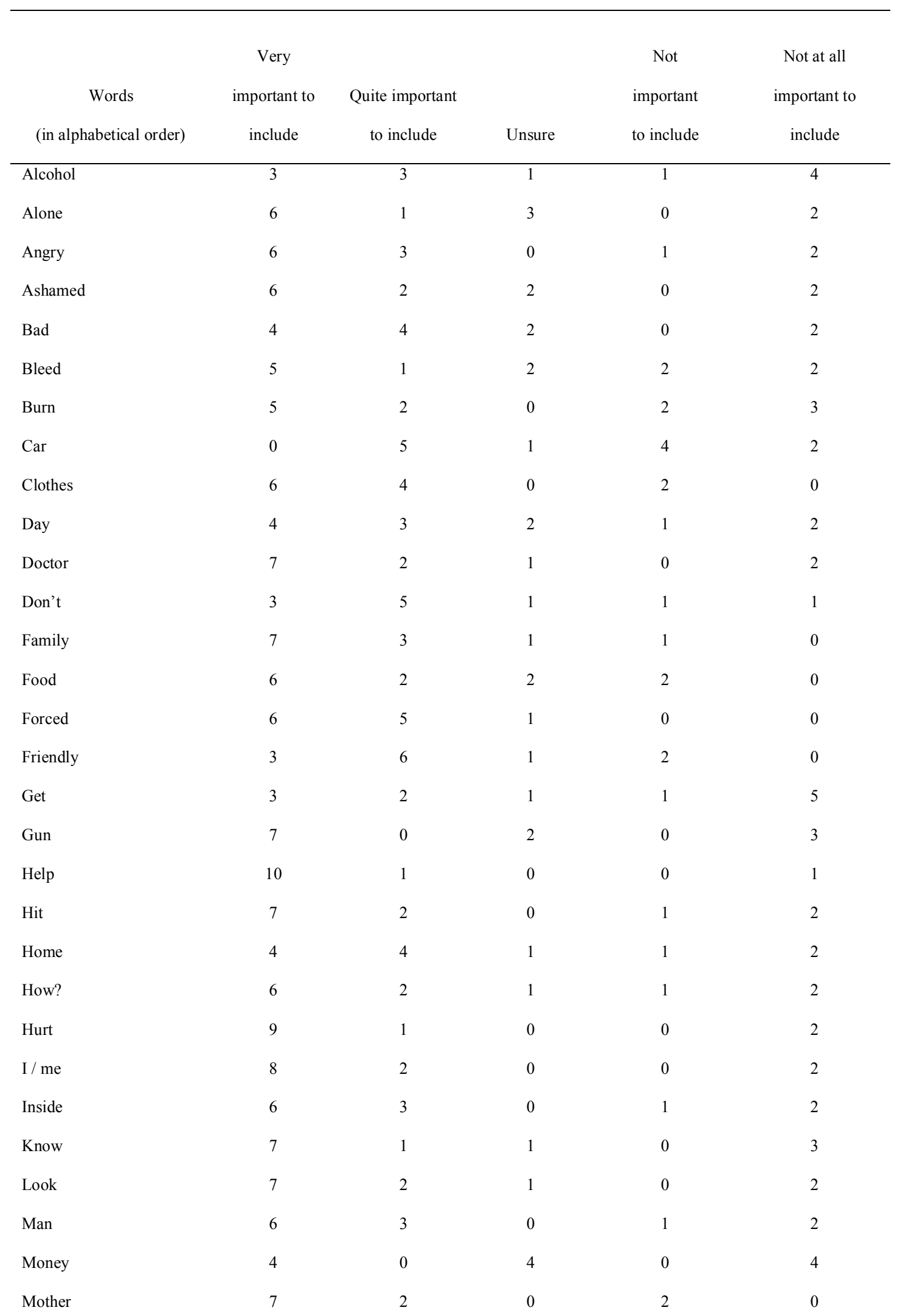




\begin{tabular}{|c|c|c|c|c|c|}
\hline Night & 2 & 4 & 3 & 0 & 2 \\
\hline Not on this board & 4 & 3 & 1 & 0 & 3 \\
\hline Outside & 5 & 1 & 2 & 0 & 3 \\
\hline Please & 5 & 4 & 0 & 0 & 2 \\
\hline Police & 8 & 2 & 0 & 0 & 2 \\
\hline Sad & 8 & 1 & 1 & 0 & 2 \\
\hline Scared & 8 & 2 & 0 & 0 & 2 \\
\hline School & 3 & 2 & 5 & 0 & 2 \\
\hline Secret & 7 & 2 & 1 & 0 & 2 \\
\hline Sex & 5 & 2 & 2 & 1 & 2 \\
\hline Shout & 7 & 2 & 0 & 0 & 3 \\
\hline Steal & 5 & 4 & 1 & 0 & 2 \\
\hline Stop & 8 & 1 & 0 & 0 & 3 \\
\hline Swear & 5 & 3 & 0 & 2 & 2 \\
\hline Sweets & 2 & 5 & 3 & 0 & 2 \\
\hline Tell & 5 & 4 & 1 & 0 & 2 \\
\hline They & 2 & 2 & 3 & 1 & 4 \\
\hline Threaten & 6 & 2 & 1 & 1 & 2 \\
\hline Toilet & 5 & 4 & 1 & 0 & 2 \\
\hline Touch & 7 & 3 & 2 & 0 & 0 \\
\hline Under & 3 & 5 & 0 & 0 & 4 \\
\hline What? & 6 & 1 & 1 & 0 & 4 \\
\hline When? & 4 & 4 & 0 & 0 & 4 \\
\hline Where? & 6 & 4 & 0 & 0 & 2 \\
\hline Who? & 6 & 4 & 0 & 0 & 2 \\
\hline Woman & 5 & 5 & 0 & 0 & 2 \\
\hline Work & 5 & 4 & 1 & 0 & 2 \\
\hline
\end{tabular}

As shown in Table 1, overall there was general agreement about the importance of the words selected, although there was not $100 \%$ agreement on any one word. Two words (forced and help) were considered important (combining very important and quite important) by 11 $(92 \%)$ of the participants and was considered to be "not important" by only one participant. 
Ten words (clothes, family, hurt, I/me, police, scared, touched, where, who, and woman) were considered important by $10(88 \%)$ of the participants. Eighteen words (angry, doctor, friendly, hit, inside, look, man, mother, please, sad, secret, shout, steal, stop, tell, toilet, touch, and work) were considered important by nine (75\%) of the participants. All of the remaining words, except for car, get, school, and they, were considered important by more than $50 \%$ of the participants. When considering the unimportant rating (combining not at all important and not important), only two words (car and get) were considered as unimportant by $50 \%$ or more of the participants.

No formal reliability measure was calculated on the checklist. However, the fact that participants responded to every vocabulary item, and that individual participant responses were distributed across the five numerical categories, provided some evidence that participants considered all of the options before responding and that they did not answer in a response-set format (Babbie \& Mouton, 2001).

No additional words were added in answer to the question "Please list any other words that you think are important".

\section{Discussion}

Before discussing the findings, several limitations of the research must be noted. First, as was already noted in the method section, the sample for this research was quite small and precluded the ability to apply any inferential statistical analyses. In addition, participants were selected purposefully, since they were all participants or alumni of Fofa. Given the sensitive nature of the topic, using persons with $\mathrm{CCN}$ with whom the authors already had a relationship was deemed important. This empowerment methodology had the potential to minimize power differentials, reduce possible exploitation, and maximize reciprocity (Cambridge \& Forrester- 
Jones, 2003). On the other hand, familiarity might have resulted in participants being eager to help and therefore behaving in a socially desirable manner by responding positively to most of the items on the checklist.

A further limitation to the study was that no test-retest or internal consistency measures of reliability were performed. As such, there is no statistical evidence that the responses would be consistent if the checklist were re-administered to these 12 individuals at a later time.

Despite these limitations, the overall findings suggest that these 12 participants concurred with most of the vocabulary selected by a variety of knowledgeable informants. The majority of participants rated most of the vocabulary items as either very important or quite important, providing strong evidence for the social validity of the vocabulary identified by stakeholders during the earlier workshop and focus groups (Bornman et al, 2011). At least two factors may have supported the success of this approach. First, the stakeholder group in the first study was comprised of individuals from a variety of backgrounds, including speech-language therapists, teachers, parents, and an individual who used AAC, rather than any single person or group. Second, an effort was made to address social and cultural diversity in this process as well - only words that were nominated by more than 1 language group were included in the final list of 57 words (Bornman et al., 2011).

Optimally, vocabulary selection may be best accomplished with input from people who use AAC themselves and who also have had experienced victimization (Bryen 2008). However, given the costs in time and the difficulty for most persons with $\mathrm{CCN}$ to travel to participate in focus groups, the validation process used in this research appears to be a viable alternative. The results reported here provide evidence that a two-part approach to identifying culturally-relevant 
vocabulary for specific contexts may be useful; first gathering input from a range of relevant stakeholders, and second, validating the vocabulary with individuals who use AAC.

For literate individuals who use AAC and have access to the Internet, technological solutions such as online focus groups (Bryen, 2008) and web crawling strategies discussed by Higginbotham (2007) may provide another means for downloading frequently read or spoken words or at least topics. However, currently this is not a viable option for many people who use AAC due to high rates of illiteracy especially in countries such as South Africa. Furthermore, lack of access to the Web or, in some cases, lack of access to computers will prevent large numbers of people from emerging countries to even explore these options. It, therefore, appears that for most people who use AAC, other informants will continue to select the vocabulary for those who lack literacy skills. Given this situation, the importance of some form of validation of the vocabulary items selected by others must be a high priority. Access to these vocabulary items is especially important when particular communication contexts necessitate specific vocabulary to ensure the health, safety, and protection of individual rights. Disclosing that you have been a victim of crime or abuse is one such context.

Surprisingly, results indicated that only one-third of the respondents reported that they had been victims of crime or abuse. This finding is in contrast to data obtained from other countries and may, in fact, be an under-representation given that anonymity could not be guaranteed. Research findings from the United States (Bryen, Carey, \& Frantz, 2003) and Israel (Reiter, Bryen, \& Shachar, 2007) suggest that individuals with disabilities were sexually abused disproportionately more than their nondisabled peers (McCarthy \& Thompson, 1997). Unfortunately, no statistics are available about crime or abuse perpetrated on individuals with disability in South Africa. 
Earlier research by Bryen et al. (2003) reported that the best victim was one who could not tell or if they could tell, they were not likely to be believed. Their findings concurred with those of the "Communication Access to Justice" program in Canada (Collier, 2012) and with Bitzchut, the Israel Human Rights Center for People with Disabilities (Primor and Lerner, 2012) noting how important it is that "communication devices ... include the vocabulary that will allow them to report the perpetrators and be believed by those to whom they report (Bryen et al. 2003, p. 133). More recently, Bryen and Wickman (2011) concluded after studying 14 cases of individuals with $\mathrm{CCN}$ who were victims of crime or abuse and who testified in court that "courts in the United States do permit individuals with limited or no functional speech to testify in court if at all possible." However, these authors cautioned that the individual with CCN must be prepared to be a credible witness. Among other factors, needed vocabulary is critical so that they can accurately describe what happened and to answer questions that might be asked. Again for people who use AAC and who can spell, this is not an insurmountable problem. However, for those without literacy skills, dependence on others to provide the needed vocabulary may be a problem underscoring the need for culturally- and contextually-relevant vocabulary.

The research reported here addresses one important aspect of social validity: subjective evaluation (Schlosser, 1999). This study provides evidence that individuals who use AAC viewed many of the 57 vocabulary items as useful in reporting crime or abuse. Future research should also examine other aspects of social validity, including social comparison (Schlosser, 1999) - for example, the extent to which access to these vocabulary items actually improves the reporting performance of individuals with $\mathrm{CCN}$.

\section{Conclusion}


With the ratification of the United Nation Convention on the Rights of Persons with Disabilities (United Nations Enable, 2012) and its articles focusing on freedom from exploitation, violence, and abuse (Article 16), freedom of expression and opinion, and access to information (Article 21), and access to justice (Article 13), there is now increasing attention to the rights of all individuals, including those with CCN (Collier, Blackstone \& Taylor, 2012). It is hoped that this increased awareness will help people who use AAC gain access to needed vocabulary, so they will no longer be silent and invisible victims of crime or abuse, both in South Africa and throughout the world.

\section{References}

Babbie, E. \& Mouton, J. (2001). The practice of social research. Oxford: Oxford University Press.

Beukelman, D. R. \& Mirenda, P. (2005). Augmentative and alternative communication:

Supporting children and adults with complex communication needs (3rd ed.). Baltimore: Paul H. Brookes.

Bornman, J, Bryen, D. N., Kershaw, P., \& Ledwaba, G. (2011). Reducing the risk of being a victim of crime in South Africa: You can tell and be heard! Augmentative and Alternative Communication, 27, 117-130.

Bryen, D. N. (2008). Vocabulary for socially-valued adult roles. Augmentative and Alternative Communication, 24, 294-301.

Bryen, D. N., (2009). Speaking up and speaking out. Two-day workshop presented at the Centre for Augmentative and Alternative Communication, University of Pretoria, Pretoria, South Africa, August 27-28, 2009. 
Bryen, D. N., Carey, A., \& Frantz, B. (2003). Ending the silence: Adults who use augmentative communication and their experiences as victims of crimes. Augmentative and Alternative Communication, 19, 123-134.

Bryen, D.N., Kershaw, P. \& Bornman, J. (2010). Communication for ALL: You can tell and be heard. Retrieved from http://disabilities.temple.edu/aacvocabulary/c4all.shtml

Bryen, D.N. \& Wickman, C. (2011) Ending the silence of people with little or no functional speech: Testifying in court. Disability Studies Quarterly. 31. Retrieved from http://dsqsds.org/article/view/1711/1759

Cambridge, P. \& Forrester-Jones, R. (2003). Using individualized communication for interviewing people with intellectual disability: A case study of user-centered research. Journal of Intellectual and Developmental Disability, 28, 5 - 23.

Carlson, F. A. C. E. (1981). A format for selecting vocabulary for the nonspeaking child. Language Speech, and Hearing Services in Schools, 12, 140-145.

Collier, B. (2012). Communication Access to Justice. Retrieved from http://www.access-tojustice.org/

Collier, B., Blackstone, S. W., \& Taylor, A. (2012). Communication access to businesses and organizations for people with complex communication needs. Augmentative and Alternative Communication, 28, 205-218.

Department of Education (1995). White Paper 5 on education and training in a democratic South Africa: First steps to developing a new system. Government Gazette 35(16312). Pretoria: Government Printer. 
Garrett, K. L. \& Huth, C. (2002). The impact of graphic contextual information and instruction on the conversational behaviours of a person with severe aphasia. Aphasiology, 16, 523536.

Graves, J. (2000). Vocabulary needs in augmentative and alternative communication: A sample of conversational topics between staff providing services to adults with learning difficulties and their service users. British Journal of Learning Disabilities, 28, $113-119$.

Higgenbotham, J. (2007). AAC WebCrawling-Communication Content from the Internet.

Retrieved from

http://www.aacrerc.com/index.php?option=com content\&task=view\&id=102\&Itemid=117

Ho, K. M., Weiss, S. J., Garrett, K. L., \& Lloyd, L. L. (2005). The effect of remnant and pictographic books on the communicative interaction of individuals with global aphasia. Augmentative and Alternative Communication, 21, 218-232.

Hurst, R. (2003). The international disability rights movement and the ICF. Disability and Rehabilitation, 25, 572-576.

Kagan, A., Winckel, J., \& Shumway, E. (1996). Pictographic communication resources manual. Toronto, Canada: Aphasia Centre, North York.

Knutson, J. F. \& Sullivan, P. M. (1993). Communicative disorders as a risk factor in abuse. Topics in Language Disorders, 13, 1-14.

McCarthy, M., \& Thompson, D. (1997) A prevalence study of sexual abuse of adults with intellectual disabilities referred for sex education. Journal of Applied Research in Intellectual Disabilities, 10, 105-125.

McClure, G. (1987). Readability formulas: Useful or useless. (An interview with J. Peter Kincaid.). IEEE Transactions on Professional Communications, 30, 12-15. 
McMillan, J. H., \& Schumacher, S. (2010). Research in education: Evidence-based inquiry (7th ed.). Boston: Pearson.

Murphy, J., \& Boa, S. (2012). Using the WHO-ICF with Talking Mats to enable adults with long-term communication difficulties to participate in goal setting. Augmentative and Alternative Communication, 28, 52-60.

Northway, R., Davies, R., Jenkins, R. \& Mansell, I. (2004). Abuse of adults with learning disabilities: An examination of policy, practice and educational implications in Wales. Pontypridd: University of Glamorgan.

Primor, S. \& Lerner, N. (2012). The Right of Persons with Intellectual, Psychosocial and Communication Disabilities to Access to Justice Accommodations in the Criminal Process. Unpublished manuscript. Jerusalem: Bitzchut.

Rackensperger, T., Krezman, C., McNaughton, D. Williams, M.B., \& D’Silva, K. (2005). “When I first got it, I wanted to throw it off a cliff": The challenges and benefits of learning AAC technologies as described by adults who use AAC. Augmentative and Alternative Communication, 21, 165-186.

Rackensperger, T (2012). Family influences and academic success: The perspectives of individuals using AAC. Augmentative and Alternative Communication, 28, 106-116.

Reiter, S., Bryen, D. N., \& Shachar, Y. (2007). Adolescents with intellectual disabilities as victims of crimes. Journal of Intellectual Disability Research, 11, 1-17.

SAPS (South African Police Services) (2007). Crime in the RSA for April to March 2001/2002 to $2006 / 2007$. Retrieved from www.saps.gov.za/statistics/reports/crimestats/2007/_pdf/rsa_total.pdf 
Schlosser, R. (1999). Social validation of interventions in augmentative and alternative communication. Augmentative and Alternative Communication, 15, 234-247.

Shane, H. C., Blackstone, S., Vanderheidern, G, Williams, M, \& DeRuyter, F. (2012). Using AAC technology to access the world, Assistive Technology, 24, 3-13.

Shewan, C.M., \& Cameron, H. (1984). Communication and related problems as perceived by aphasic individuals and their spouses. Journal of Communication Disorders, 17, 175-187.

Sudsawad, P. (2009). Developing a social validation model for effective utilization of disability and rehabilitation research. Retrieved from http://www.researchutilization.org/matrix/generate/switzerreport.html

Sullivan, P. M. (2009). Violence exposure among children with disabilities. Clinical Child and Family Psycological Review, 12, 196-216.

Sullivan, P. M., \& Knutson, J.F. (2000). Maltreatment and disabilities: A population-based epidemiological study. Child Abuse and Neglect, 24, 1257-1273.

United Nations Enable (2012). Convention on the Rights of Persons with Disabilities, Retrieved from http://www.un.org/disabilities/default.asp?id=259

Van de Sandt-Koenderman, M. W. M. E. (2004). High-tech AAC and aphasia: Widening horizons? Aphasiology, 18, 245-263.

Wolf, M. M. (1978). Social validity: The case for subjective measurement or how applied behavior analysis is finding its heart. Journal of Applied Behavioral Analysis, 11, 203214. 